\title{
Purification of Sugarcane Juice (Saccharum officinarum L.) Using Chitosan Membrane with Dead-End Flow System
}

\author{
Yusuf Hendrawan ${ }^{\mathrm{a}, 1}$, Ayu Diyaratnasari ${ }^{\mathrm{a}, 2}$, Sandra Malin Sutan ${ }^{\mathrm{a}, 3}$, Muchnuria Rachmawati ${ }^{\mathrm{b}}$, \\ Yusuf Wibisono ${ }^{\mathrm{a}, 4}$ \\ ${ }^{a}$ Department of Agricultural Engineering, University of Brawijaya, Jl. Veteran, Malang, 65145, Indonesia \\ E-mail: ${ }^{1} y u s u f \_h @ u b . a c . i d ;{ }^{2}$ ayu135100201111048@gmail.com; ${ }^{3}$ sandra.msutan@ub.ac.id; ${ }^{4}$ y_wibisono@ub.ac.id \\ ${ }^{b}$ Department of Agricultural Product Technology, University of Brawijaya, Jl. Veteran, Malang, 65145, Indonesia \\ E-mail: muchnuria@yahoo.com
}

\begin{abstract}
The purification process of sugarcane juice in a sugar factory mostly uses sulphitation process, separating clear juice from dirty juice using a sedimentation system. Impurities on the processing of sugarcane juice will further cause difficulties, the formation of color, an increase in viscosity, and reducing sugar recovery. Membrane purification technology is offered to overcome these problems. This study aims to determine the effect of chitosan and acetic acid on the performance of chitosan membranes in the clearance of sugarcane juice and to find the best concentration of chitosan and acetic acid for the purification process of sugarcane juice. The filtration process was performed by using the chitosan membrane to process a clear sugarcane juice sample from the pretreatment result, which is assumed as clear juice product from sulphitation process in sugar factory. The results showed that (1) the result of pretreatment had the value from TSS (Total Soluble Solids) of $15.4 \%$; turbidity of 82.33 NTU; and the ICUMSA (International Commission for Uniform Methods of Sugar Analysis) colour of 14970.02 IU. (2) After filtration using membrane, better quality of pretreatment clear sugarcane juice is obtained, characterized by increasing chitosan concentration at each acetic acid level, rejection value of TSS, turbidity, and ICUMSA colour. (3) The best treatment result based on Zeleny multiple attribute method is found in chitosan membrane with concentration of $4 \%$, acetic acid concentration of $1.5 \%$ to inject TSS until reaching $\mathbf{1 2 . 6 4 \%}$, ICUMSA until reaching $\mathbf{9 . 8 9 \%}$, and rejection of turbidity until reaching $\mathbf{6 3 . 6 1 \%}$. Higher chitosan concentration caused small pore size of the membrane.
\end{abstract}

Keywords - acetic acid; chitosan; membrane; sugarcane juice purification.

\section{INTRODUCTION}

The process of purifying sugarcane juice in sugar factories is mostly performed by using sulphitation process [1]. However, this sulphitation method is still less effective in purifying the juice. Generally, the result is still below the standard because of the deposition system, the sugarcane juice still contains colloidal particles and macromolecules so that the cane juice still looks cloudy. This, unfortunately, leads to production inefficiency and low quality of sugar [2]. Membrane technology can act as a unit of separation operations on different types of substrates with different end products. At present, there has been a lot of growing researches on the utilization of natural polymers as membranes. Chitosan is a biopolymer that can be used as a membrane-making ingredient [3]-[5]. A good chitosan solvent is an acetic acid [6]-[9]. Cahyaningrum [10] reported that the dead-end system in the chitosan membrane was tested and was able to purify uric acid concentrations up to $90 \mathrm{mg} / \mathrm{l}$ with a filtered uric acid amount of $48.23 \mathrm{mg} / \mathrm{l}$. Ghani [11] conducted a study using a dead-end purification cell that was used to characterize the purification performance of polyamide-6/chitosan membranes. The results show that the nanofibrous polyamide-6/chitosan membrane has enormous potential in removing dyes from aqueous solutions with purification yields of $96 \%$; Solophenyl Red 3BL of 95\% and Polar Yellow GN. Rahimi [12] modified the ultra-purification polyethersulfone (PES) membrane by mixing O-carboxymethyl chitosan/ $/ \mathrm{Fe}_{3} \mathrm{O}_{4}$ nanoparticles in a PES solution (14\% by the polymer weight) and cast it through a phase inversion process. Membranes with four different weight percentages of O-Carboxymethyl chitosan binding $\mathrm{Fe}_{3} \mathrm{O}_{4}$ magnetic nanoparticles (OCMCs$\mathrm{Fe}_{3} \mathrm{O}_{4}$ ) to PES were tested with a dead-end system. The result shows that the membrane can increase the flux of pure water. Rupiasih [13] examines the possibility of chitosan membranes used as filters to remove silver (Ag) from the Xray film processing waste. Some chitosan membranes such 
as M1, M2, M3, and M4 have been prepared on purpose, and the purification process is performed by using dead-end filtering methods. The results showed that the M2 chitosan membrane gave the highest purification coefficient (Rcoeff) of $99.9 \%$, with pure water flux and product flux, respectively, of $2972.56 \mathrm{~L} / \mathrm{m}^{2} \mathrm{~h}$ and $1761.18 \mathrm{~L} / \mathrm{m}^{2} \mathrm{~h}$. There are more researches on the effectiveness of chitosan membranes by using a dead-end flow system in various applications [14]-[17].

Previously the purification of sugarcane juice with membranes was conducted by Luo [18] by using an integrated membrane process consisting of tubular loose ultra-purification (UF), UF spiral-wound tight and spiralwound NF. The results showed that the removal of color and turbidity reached $96.55 \%$ and $99.99 \%$, respectively. Several other studies which have succeeded in purifying sugar cane juice with membrane technology include Bhattacharjee [19]; Conidi [20]; Pal [21]; and Urosevic [22]. However, there has been no attempt to purify sugarcane juice by using the chitosan membrane. By referring to previous research on the potential of the chitosan membrane in reducing metal and dye waste, it is expected that the chitosan membrane can improve the purification of sugarcane juice (Saccharum officinarum L.). The purpose of this study is to determine the effect of chitosan and acid concentration in purifying sugar cane juice and to find the best concentration of chitosan and acetic acid in purifying sugar cane juice.

\section{MATERIALS AND METHODS}

The research was conducted in the Laboratory of Food and Agricultural Product Processing Technology, Laboratory of Natural Resource and Environmental Engineering, and Laboratory of Basic Chemistry in the Department of Agricultural Engineering, Universitas Brawijaya, Indonesia. This research is divided into two stages. In the first phase, the research was focused on membrane preparation and production. In the second stage, the application of membranes, which has been made on sugar cane (Saccharum officinarum L.) shows the result of pretreatment.

The tools used in this research include Beaker glass (Pyrex Iwaki $250 \mathrm{ml}$ ); Digital Scales (Mettler PM460, The Netherlands); Glass plate; Oven (Memmert T5052); Measuring cup (Pyrex Iwaki $100 \mathrm{ml}$ ); Petri dish (Steriplan); Measuring flask (Pyrex Iwaki $100 \mathrm{ml}$ ); Hand refractometer (ATAGO) to measure TSS (Total Soluble Solids); $\mathrm{pH}$ meter (ATC) as pH measure; Spectrophotometer (Libra S12) to measure the color of sugarcane juice at $420 \mathrm{~nm}$ wavelength; and Turbidimeter (Lovibond) to measure turbidity. The materials used in this study include chitosan shrimp as a membrane-making ingredient; glacial acetic acid as a chitosan solvent in which acetic acid has a concentration of 100\%; Aquades (Hydrobats) as solvents of $\mathrm{NaOH}$ and lime milk; $\mathrm{NaOH}$ Pro Analysis as a non-solvent agent; Lime milk and flocculent as pretreatment ingredients of sugarcane juice; and sugarcane juice as bait sample (green sugarcane type from Tulungagung, Indonesia).

\section{A. Membrane Making Procedure}

The making of chitosan membrane consists of several stages [5] which are: chitosan with three different mass of 2 grams; 3 grams; and 4 grams dissolved in $75 \mathrm{ml}$ of acetic acid solution $(\mathrm{CH} 3 \mathrm{COOH})$ each of $1 \% ; 1.5 \% ; 2 \%(\mathrm{v} / \mathrm{v})$. Thus, the dope of chitosan concentration obtained is $2.67 \%$, $4 \%$, and $5.33 \%(\mathrm{w} / \mathrm{v})$. Further, it is stirred until appearing homogeneous by using a mechanical stirrer for 6 hours with a speed of stirring from $300 \mathrm{rpm}$ to form dope chitosan. Dope chitosan is then deposited for \pm two days with room temperature to remove the bubbles after poured into the molding glass as a media. It is then baked at $40{ }^{\circ} \mathrm{C}$ for 24 hours to dry. The dried membrane is then aerated for \pm 1 hour. The subsequent membrane was immersed in $4 \%$ of $\mathrm{NaOH}(w / v)$ solution for 1 hour at room temperature. Coagulated membranes are then washed repeatedly by using running water to remove $\mathrm{NaOH}$ residual solution. Flow diagram of the chitosan membrane production process can be seen in Fig. 1.

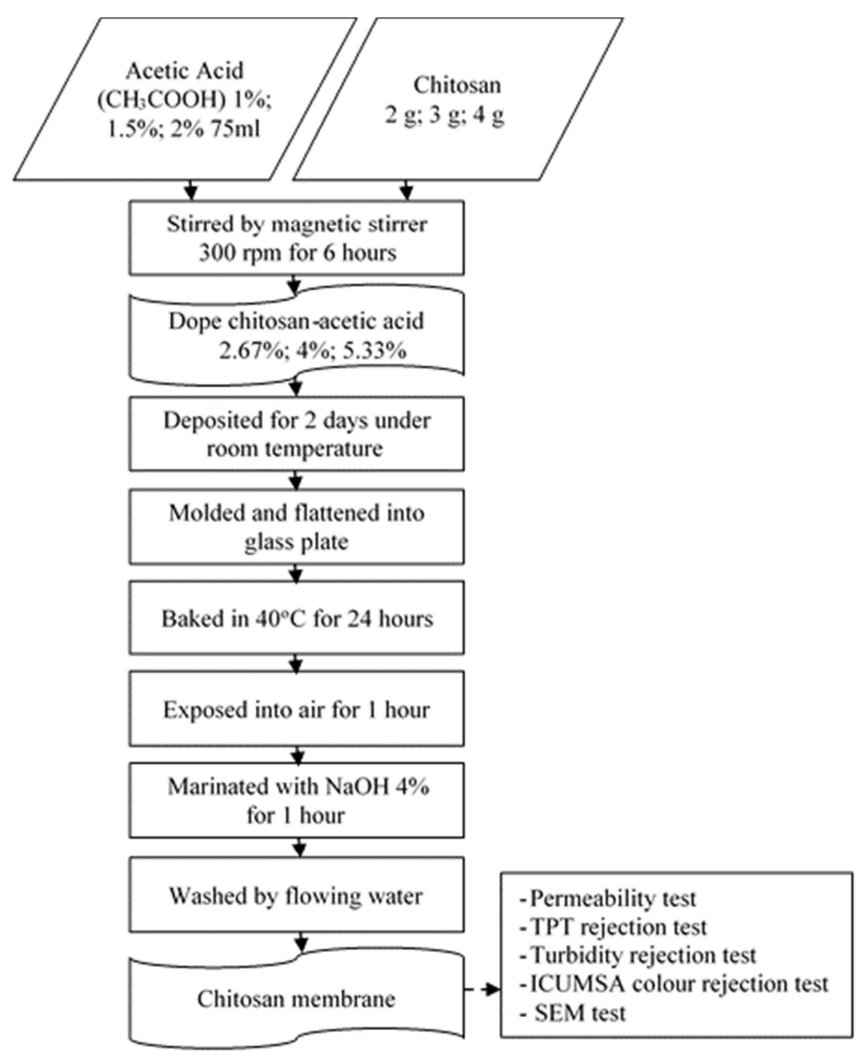

Fig. 1 The process of making chitosan membranes

\section{B. Sugarcane Juice Pretreatment Procedure}

The raw sugar from sugarcane milling was measured in TSS and initial $\mathrm{pH}$ by using a refractometer and $\mathrm{pH}$ meter. The raw sugarcane juice is heated to $75{ }^{\circ} \mathrm{C}$ and then put in lime milk until the $\mathrm{pH}$ of juice reaches 8.5. The addition of lime milk is given to obtain an alkaline atmosphere in the juice, due to the residual compound found in juice. The procedure is followed by adding flocculant as $0.1 \%$ as much as $3 \mathrm{ml}$ (in each litter juice), then reheated until $90{ }^{\circ} \mathrm{C}$ for 5 minutes.

\section{Membrane Permeability Test}

The membrane is cut in a circle with a diameter of $4.8 \mathrm{~cm}$ according to the diameter of the flux test apparatus. During the preparation procedure, some materials used are 
measuring cups, timers, and digital scales to measure the amount of fluid passing through the membrane. The process is repeated 3 times on each membrane concentration to obtain an average yield. Membrane permeability is seen from the flux value. The larger pore size of the membrane indicates a large volume produced as a flux value. The determination of flux as the unit of time can be calculated by equation 1 :

$$
J=\frac{V}{A x t}
$$

Where: $\mathrm{J}=$ flux $\left(\mathrm{L} / \mathrm{m}^{2}\right.$.hour $) ; \mathrm{V}=$ volume $(\mathrm{L}) ; \mathrm{A}=$ membrane cross-sectional area $\left(\mathrm{m}^{2}\right) ; \mathrm{t}=$ measurement time (hours).

\section{Membrane Permittivity Test}

Sugarcane juice, which is the result of pretreatment (feed) is obtained from initial analysis in the form of TSS, turbidity, and International Commission for Uniform Methods of Sugar Analysis (ICUMSA) test. The membrane is inserted into a purification cell, and then the purification cell is filled with sugarcane juice as much as 1 liter and is given the pressure of 1 bar. The permeate of each process is accommodated on a measuring cup. The permeate results are tested on TSS, turbidity, and color ICUMSA. The equation to find the rejection coefficient of the membrane is shown in equation 2:

$$
R=\left(1-\frac{C p}{C f}\right) \times 100 \%
$$

Where: $\mathrm{R}=$ rejection coefficient $(\%) ; \mathrm{Cp}=$ permeate concentration; $\mathrm{Cf}=$ feed concentration (particles in the feed).

\section{E. Analysis method}

TABLE I

\begin{tabular}{|c|c|c|c|}
\hline \multirow{2}{*}{$\begin{array}{c}\text { The concentration } \\
\text { of Acetic Acid } \\
\left(\mathrm{CH}_{3} \mathrm{COOH}\right)(\%)\end{array}$} & \multicolumn{3}{|c|}{ Concentration of Chitosan (\%) } \\
\hline & $2.67 \%$ & $4 \%$ & $5.33 \%$ \\
\hline $1 \%$ & $\begin{array}{l}\text { Acetic Acid 1\% } \\
\text { Chitosan } 2.67 \%\end{array}$ & $\begin{array}{c}\text { Acetic Acid 1\% } \\
\text { Chitosan 4\% }\end{array}$ & $\begin{array}{l}\text { Acetic Acid 1\% } \\
\text { Chitosan 5.33\% }\end{array}$ \\
\hline $1.5 \%$ & $\begin{array}{c}\text { Acetic Acid } 1.5 \% \\
\text { Chitosan } 2.67 \%\end{array}$ & $\begin{array}{c}\text { Acetic Acid 1.5\% } \\
\text { Chitosan } 4 \%\end{array}$ & $\begin{array}{c}\text { Acetic Acid 1.5\% } \\
\text { Chitosan 5.33\% }\end{array}$ \\
\hline $2 \%$ & $\begin{array}{l}\text { Acetic Acid 2\% } \\
\text { Chitosan } 2.67 \%\end{array}$ & $\begin{array}{c}\text { Acetic Acid 2\% } \\
\text { Chitosan 4\% }\end{array}$ & $\begin{array}{l}\text { Acetic Acid 2\% } \\
\text { Chitosan 5.33\% }\end{array}$ \\
\hline
\end{tabular}

COMBINATION TREATMENTS OF CHitosan MEMBRANE
This research consists of 2 factors which are: chitosan concentration and acetic acid concentration. The first factor and the second factor consist of 3 levels; therefore, nine combinations are obtained, as seen in Table 1 , and is repeated three times to get 27 treatment combinations. Data analysis was performed by using a two-way analysis of variance (Two Way ANOVA). If there is any influence between treatments, then it proceeds with the Least Significant Difference (LSD) test of $1 \%$ and $5 \%$. The best treatment selection procedure is based on Multiple Attribute Zeleny. The ideal value of the parameters for the determination of the best treatment in this study is shown in Table 2. The best treatment membrane results will then be tested through Scanning Electron Microscopy (SEM) method to determine the morphology of the membrane.

TABLE II

THE IDEAL PARAMETER VALUE FOR BEST TREATMENT DETERMINATION

\begin{tabular}{|c|c|}
\hline Parameter & Assumption of ideal value \\
\hline Permeability & Highest \\
\hline TSS Rejection & Highest \\
\hline ICUMSA Color Rejection & Highest \\
\hline Turbidity Rejection & Highest \\
\hline
\end{tabular}

\section{RESULTS AND DISCUSSION}

\section{A. Effect of chitosan and acetic acid on water permeability}

The water permeability value is obtained by measuring the water flux value divided by the membrane operating pressure. The membrane is expected to have a tight pore so that it can work optimally in its application for the purification of pretreatment juice. Membrane permeability testing was performed by using a flux test apparatus with a dead-end method and by using water with a pressure of 1 bar, and the data was collected every 5 seconds for 5 minutes. Permeability is affected by the number and size of the pore, the pressure applied, and the thickness of the membrane [23]-[26]. Permeability is defined as the amount of permeate volume passing through one unit of membrane area in a given time unit in the presence of a pressure force [27]. The relationship of chitosan concentration and acetic acid with water permeability can be seen in Fig. 2.

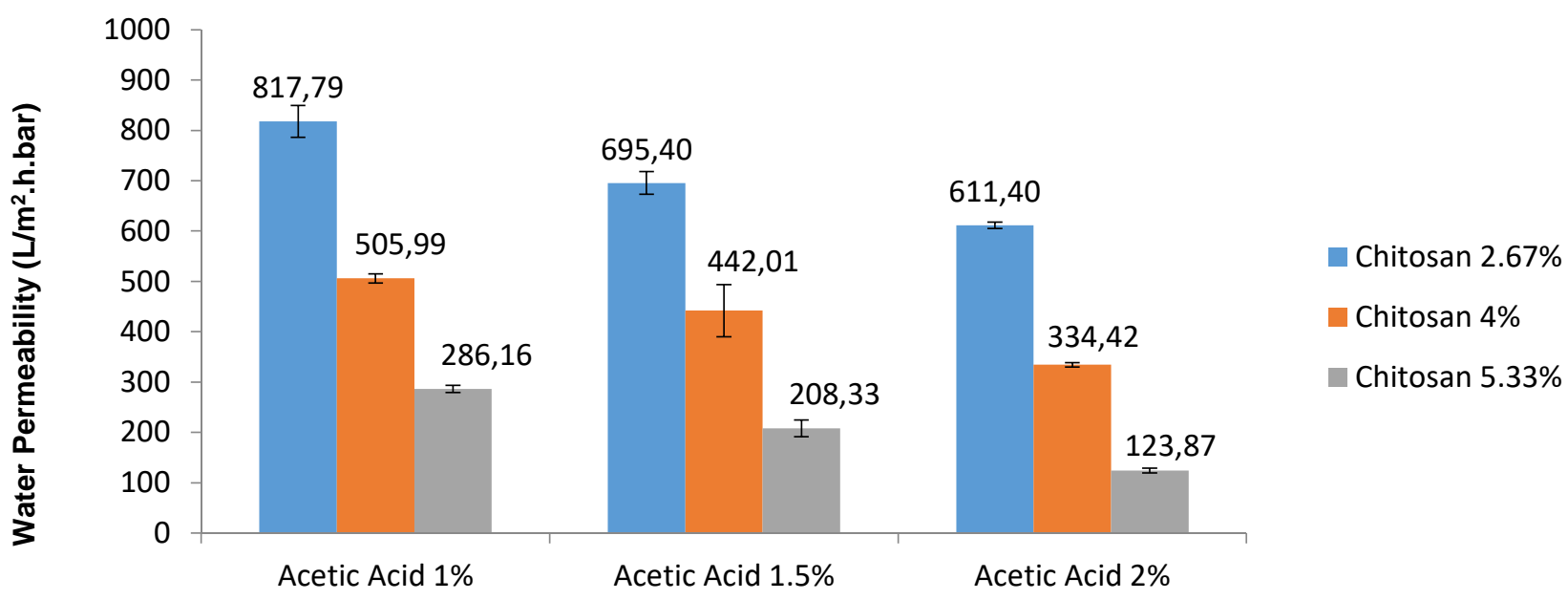

Fig. 2 Relation of chitosan and acetic acid concentration with water permeability 
Based on Fig. 2, it is apparent that the permeability value tends to decrease chitosan concentration at each acetic acid level. The largest permeability generated from this test is on the chitosan membrane with a concentration of $2.67 \%$ and $1 \%$ acetic acid of $817.79 \mathrm{~L} / \mathrm{m}^{2}$.hour.bar. The smallest permeability is on the membrane concentration of $5.33 \%$ chitosan and $2 \%$ acetic acid of $123.87 \mathrm{~L} / \mathrm{m}^{2}$.hour.bar. The higher the permeability value, the easier the solution is needed to pass through the membrane. Low chitosan concentrations may cause more magnificent molecule and the space formed on the hydrogel membrane providing a large space for water molecules to pass through the membrane. Conversely, high chitosan concentrations cause the distance between chitosan molecules increasingly tight and narrow the space on the membrane, which cannot easily be crossed by water molecules. Another factor is higher acetic acid, which creates more soluble chitosan and smoother pores. On the other hand, more insoluble chitosan will cause a hole in the membrane. According to Wang [28] and Liu [29], the large flux value is influenced by the membrane-forming concentration; the higher the concentration of membrane-forming polymer, the resulting membrane is denser, resulting in smaller flux. The water permeability graph of all membranes in every 5 seconds can be seen in Fig. 3.

Based on Fig. 3, it is apparent that the value of water permeability in all variations of the chitosan membrane has the same fluctuating trend. Membrane behavior during the purification process will not be the same every time but tends to rise and fall. This is thought to be because in one area of the membrane surface, there is a non-uniform shape, quantity, and size of the pore.

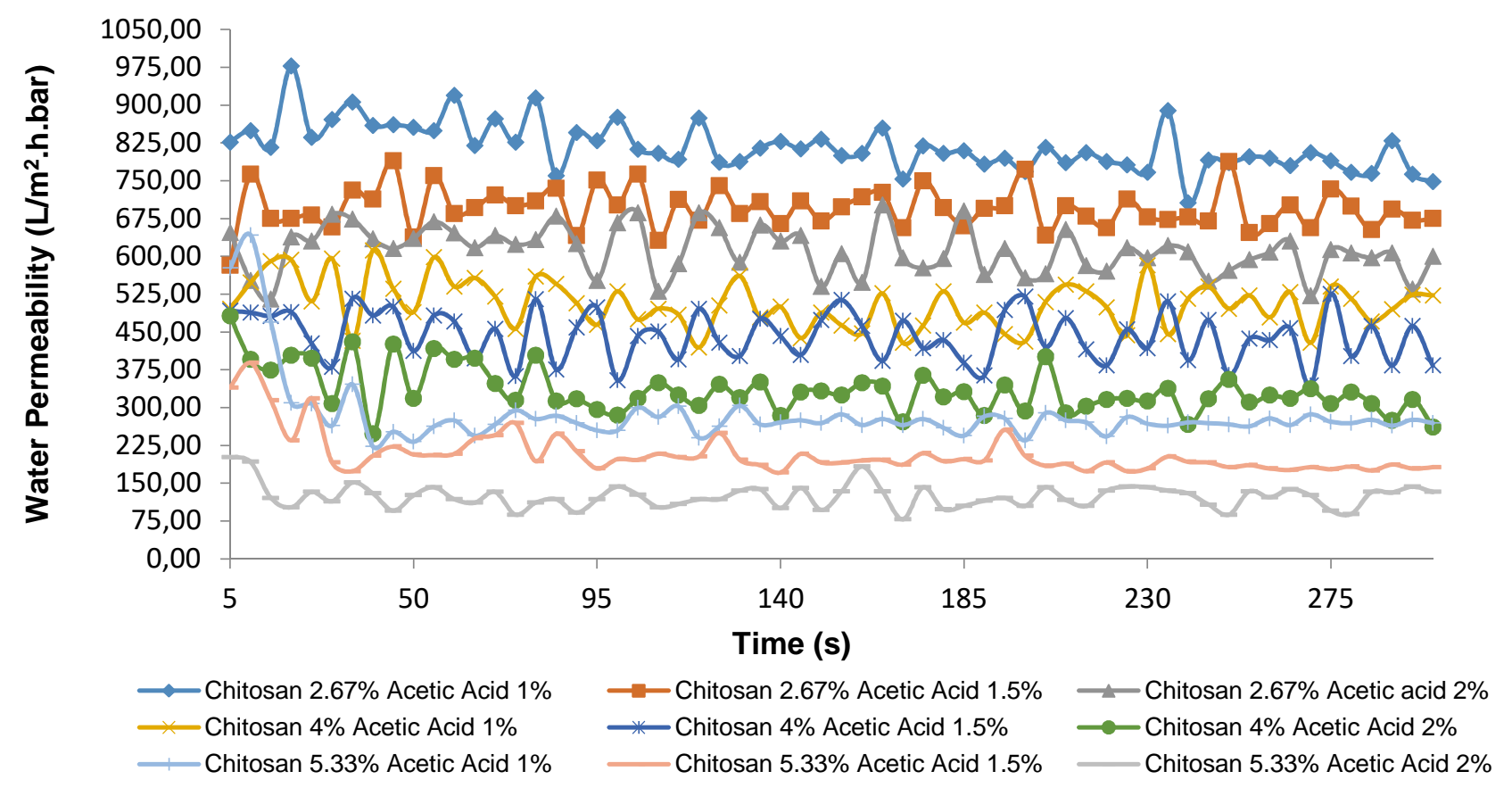

Fig. 3 Water permeability of all membranes every 5 seconds

Thus, during the purification process, there may be an opening and closing pore, causing the fluctuating flux value. According to the research, the resulting membrane is included in the type of micro purification membrane, in which the minimum permeability value measured is 123.87 $\mathrm{L} / \mathrm{m}^{2}$.hour.bar by using the 1 bar pressure of driving force. According to the literature, the micro purification membrane has a pressure range of 0.1 to 2.0 bar and the permeability limit is $>50 \mathrm{~L} / \mathrm{m}^{2}$.hour.bar; the ultra-purification membrane has a pressure range of 1 - 5 bar, and the permeability limit is $10-50 \mathrm{~L} / \mathrm{m}^{2}$.hour.bar; the nano-purification membrane operates at a pressure ranging from 5 to 20 bar and permeability limit of $1.4-12 \mathrm{~L} / \mathrm{m}^{2}$.hour.bar; reverse osmosis membranes operate at a pressure ranging from 10 to $100 \mathrm{bar}$, and permeability limits reach $0.05-1.4 \mathrm{~L} / \mathrm{m}^{2}$.hour.bar [27].

Based on ANOVA, treatment factor, factor K (Chitosan), and factor A (acetic acid) in water permeability value have a very real effect (Fcount > Ftabel 0.01). Therefore, it is necessary to perform LSD with the level of $5 \%$ and $1 \%$ to find out the difference between each treatment interaction.
The coefficient of diversity obtained is $5.05 \%$ which is the category of medium diversity. The results of LSD statistical tests show the effect of chitosan and acetic acid concentrations having significant differences in water permeability. This is because no treatment has the same notation after analyzed with LSD 0.05 and LSD 0.01 .

\section{B. The effect of chitosan and acetic acid on the permeability of sugarcane juice}

Based on Fig. 4, it is apparent that the permeability value of sugarcane juice tends to decrease along with increasing chitosan and acetic acid concentration. The largest permeability resulting from this test was on the chitosan membrane with a concentration of $2.67 \%$ and $1 \%$ acetic acid by $194.67 \mathrm{~L} / \mathrm{m}^{2}$.hour.bar. Meanwhile, the smallest permeability is found on the chitosan membrane with a concentration of $5.33 \%$ and $2 \%$ acetic acid of 45.32 $\mathrm{L} / \mathrm{m}^{2}$.hour.bar, because of the low concentration of chitosan will cause a fewer number of chitosan molecules in the membrane; thus, causing more space to form on the 
membrane. Conversely, more chitosan concentrations found in the membrane create a smaller distance between the molecules becomes a smaller and denser structure of membrane forms. At higher solvent (acetic acid) concentrations, the solvents will be replaced faster by nonsolvent and form small and tight pores, resulting in smaller fluxes. According to some researchers [5], [30], [31], the addition of chitosan concentration causes a decrease in permeability, higher concentration of chitosan solution, and increasing viscosity of the solution. The clear sugarcane juice permeability graph of all membranes every 5 seconds can be seen in Fig. 5 .

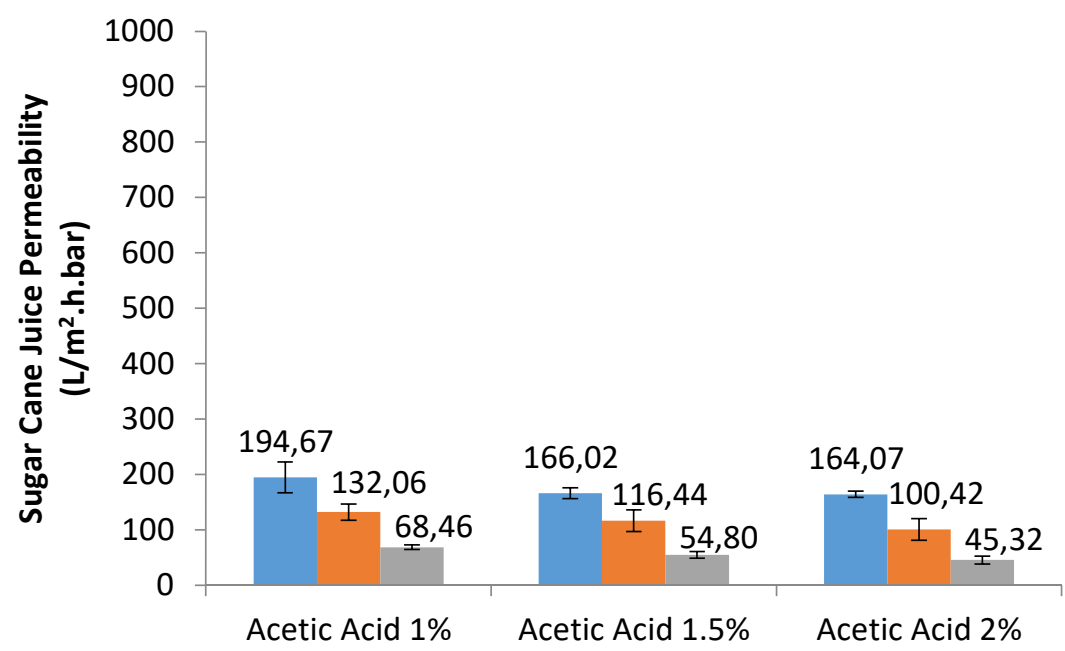

Fig. 4 The relationship of chitosan and acetic acid concentration with clear sugarcane juice permeability

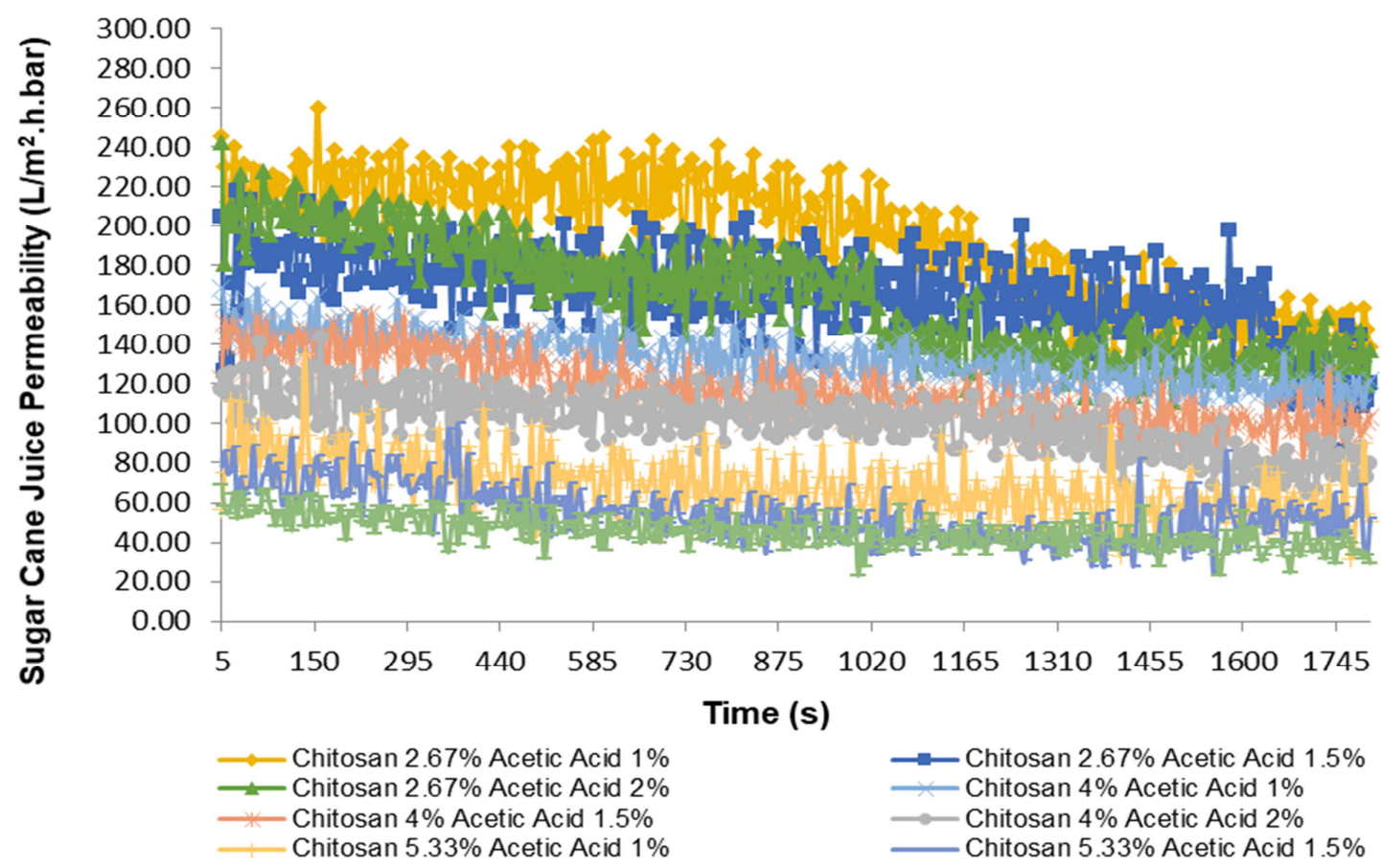

Fig. 5 Clear sugarcane juice permeability of all membranes every 5 seconds of 30 minutes

Based on Fig. 5 it is obvious that the value of permeability of clear sugarcane juice decreases within 30 minutes longer. This is due to the longer purification time, where there will be blockage (fouling) on the surface of the membrane due to accumulation of larger particles than the membrane pore size such as fiber (cellulose), organic matter (ash), wax creating more accumulated layer (cake) on the membrane surface. The thickness of the "cake" will continue to increase and result in decreasing flux as time increases. The parameters which affect the occurrence of fouling on the membrane are the concentration of bait. A high concentration in the feed will increase the density of the feed solution and the viscosity. The high viscosity will decrease the diffusivity of the solution. Low diffusivity will complicate the feed through the membrane, which leads to the formation of thick layers in the membrane, thus clogging the membrane pores [32].

Based on the ANOVA showing the group (replication) and the interaction factor of $\mathrm{K} * \mathrm{~A}$ (chitosan and acetic acid), the test resulted in an insignificant effect (Fcount $<$ Ftabel $0.05<$ Ftabel 0.01). Meanwhile, the factor of treatment, factor K (Chitosan) and factor A (acetic acid) have a genuine 
effect (Fcount $>$ Ftabel 0.01 ) to the value of permeability of clear sugarcane juice, so it is necessary to conduct LSD with the level of $5 \%$ and $1 \%$ to identify the difference between each treatment interaction. The coefficient of diversity obtained is $13.30 \%$, which is considered to have a medium diversity category. The coefficient of diversity is used to indicate the degree of accuracy. The smaller value of the coefficient of diversity will lead to a better degree of accuracy and validity. The LSD statistical test of each treatment generally shows that chitosan and acetic acid variations have significant differences in the sugarcane juice flux. However, some treatments have the same notation. This similarity means that the membranes with such treatments have no significant difference in their effect on the permeability value of clear sugarcane juice.

\section{Membrane rejection coefficient to total soluble solids (TSS) of clear sugarcane juice}

Figure 6 shows the increasing level of chitosan and acetic acid concentration, causing the increase of membrane rejection coefficient to the total concentration of TSS of clear sugarcane juice. The results of the test demonstrate that the smallest TSS rejection coefficient is the chitosan membrane with a concentration $2.67 \%$ and $1 \%$ acetic acid with a rejection coefficient value of $5.09 \%$. Membrane with a coefficient value of most significant TSS rejection is the chitosan membrane with a concentration of $5.33 \%$ and $2 \%$ acetic acid with a rejection coefficient value of $21.30 \%$. This is presumably because the membrane structure is closely related to the degree of membrane rejection and membrane transport mechanism. Membrane structure and pore are influenced by chitosan mass in making chitosan solution. Greater concentration of polymer (chitosan) creates a smaller size of pore in the membrane because the higher concentration of chitosan creates more density in membrane pore size resulting in an increased coefficient of TSS rejection by the membrane. Based on research conducted by several researchers [33]-[35], treatment using chitosan filter resulted in smaller TSS values. The more the number of chitosan then the TSS value of the well water is lower. The decrease in the number of dissolved solids is thought to be due to the chitosan used as a filter capable of binding to soluble solids contained in water.

The components of solute in cane juice include water, sucrose, salt, protein, dyestuff, gums, starch, and lignin. The solute component, such as starch, is suspected to be suspended on the surface and pores of the chitosan membrane because it has a particle size similar to the pore size range of the microfiltration membrane between 0.05 and $10 \mu \mathrm{m}$ [27]. Jane [36] states that starch has a particle diameter size ranging from $5-15 \mu \mathrm{m}$. While the components that allegedly pass through the pore membrane chitosan include water, sucrose, salt, protein, dyes, gums, and lignin. The size of one water molecule is minimal, generally centered around $3 \mathrm{~A}(0.3 \mathrm{~nm})$. According to Kaszuba [37] sucrose has a molecular diameter size between $0.9-0.98 \mathrm{~nm}$. Furthermore, Erickson [38] reported that the protein has a particle size ranging from 1.1 to $5.21 \mathrm{~nm}$. The salt has a molecular diameter size of 0.0007 microns or $0.7 \mathrm{~nm}$. At the same time, the average particle size of the chlorophyll pigment is $27.26 \pm 3.62 \mathrm{~nm}$. Soumya [39] states that the particle size of gums is between $20-50 \mathrm{~nm}$. According to Vainio [40] lignin particles have a thickness between 1 - 3 $\mathrm{nm}$ with a particle size of $\pm 3.5 \mathrm{~nm}$. When compared to the pore size of the microfiltration membrane between 0.05 and $10 \mu \mathrm{m}$ [27], the size of water molecules, sucrose, salt, protein, and chlorophyll dye is smaller than the pore of the microfiltration membrane, so it is suspected to pass through the pores of the membrane.

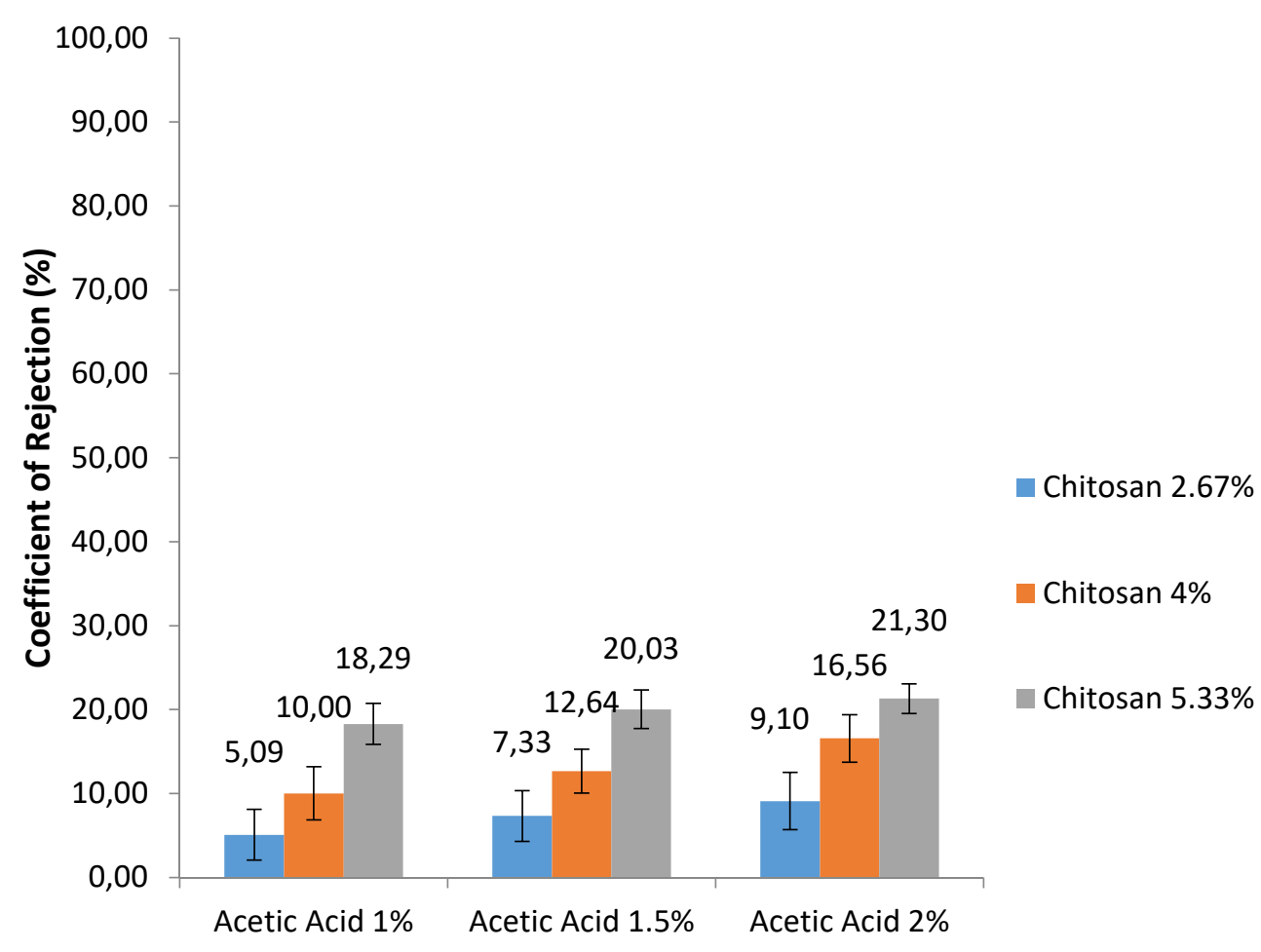

Fig. 6 Effect of chitosan and acetic acid concentration on TSS rejection in clear sugarcane juice 
Based on the ANOVA calculation, the interaction factor of $\mathrm{K} * \mathrm{~A}$ (chitosan and acetic acid) yields an insignificant effect (Fcount < Ftabel 0.05 < Ftabel 0.01). Meanwhile, factor (replication), treatment, factor $\mathrm{K}$ (Chitosan), and factor A (acetic acid) have a genuine effect (Fcount $>$ Ftabel 0.01 ) to the value of TSS rejection, so it is necessary to conduct LSD of $5 \%$ and $1 \%$ to find out the difference between each treatment interaction. The coefficient of diversity obtained is $14.80 \%$, which is considered in the medium diversity category. Based on LSD statistical test, it is obvious that the variation of chitosan and acetic acid has a significant difference to TSS rejection of clear sugarcane juice. However, some treatments have the same notation. The similarity of this notation means that the membranes with such treatments have no significant difference in their effect on the value of TSS rejection.

\section{Membrane rejection coefficient of ICUMSA color on clean sugarcane juice}

Figure 7 shows the increasing level of chitosan and acetic acid concentration, causing the increase of membrane rejection coefficient on ICUMSA color. The smallest ICUMSA color rejection coefficient is the chitosan membrane with a concentration of $2.67 \%$ and $1 \%$ acetic acid with a rejection coefficient value of $3.86 \%$. The membrane with the highest ICUMSA color rejection coefficient value is the chitosan membrane with a concentration of $5.33 \%$ and $2 \%$ acetic acid with a rejection coefficient value of $15.23 \%$. This is allegedly due to the higher concentration of chitosan with denser particles, causing the small pore size of the membrane. In addition to higher solvent (acetic acid) concentrations, the solvents will be replaced faster by nonsolvent, forming small and tight pores. Based on the result of the research, it is assumed that the micro purification membrane is ineffective to separate the color. The largest ICUMSA color rejection value is only $15.23 \%$. Based on the literature for dye removal, the nano purification membrane is used. The nano purification membrane has a pore size of $0.001 \mu \mathrm{m}$. Nano purification may be used for several types of separations, such as demineralization, dyestuff removal, and desalination [41], [42].

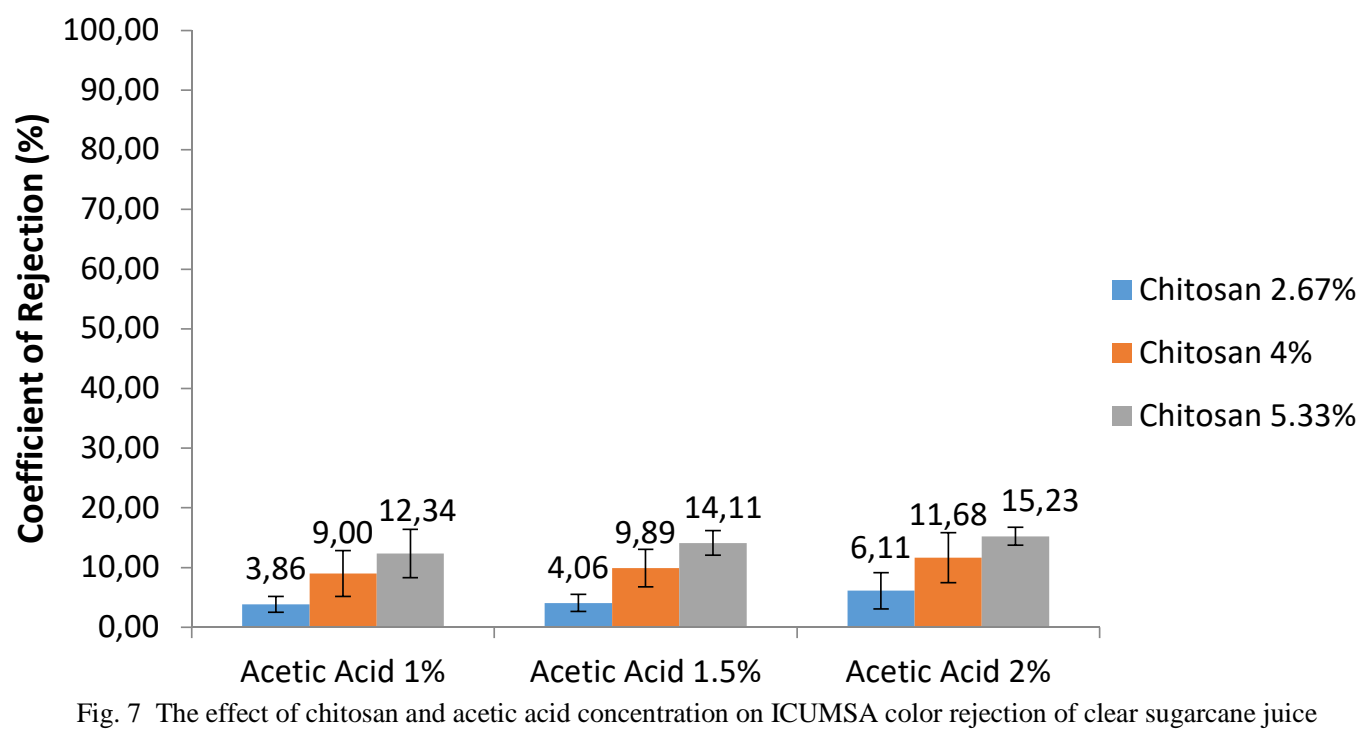

Based on the ANOVA calculation, group factor (replication), treatment, factor $\mathrm{K}$ (chitosan), and factor $\mathrm{A}$ (acetic acid) have a very real effect (Fcount $>$ Ftabel 0.01) to ICUMSA color rejection value, with LSD level of 5\% and $1 \%$ to find out the differences between each treatment interaction. The coefficient of diversity obtained is $14.21 \%$, which is in the category of medium diversity. LSD statistical tests of each treatment on ICUMSA color rejection show that several treatments have similar notation. This similarity means that the membranes with these treatments have no significant difference in their effect on the color values of ICUMSA of clear sugarcane juice.

Sugarcane color comes from the color of raw material (sugarcane) and chemical decomposition (browning) due to oxidation reaction. The dye derived from sugar cane is derived from the natural pigment of sugarcane, among others, chlorophyll and carotene. Another factor that can affect the color of sugarcane juice is the condition of sugarcane when milled (clean sugarcane or dirty sugarcane). Microfiltration membranes can separate colors derived from suspended substances such as organic matter (ash) and dust. Ghosal [43] states that the ash has a particle diameter size> $10 \mu \mathrm{m}$. In comparison, the dust particles have sizes ranging from 0.1 $100 \mu \mathrm{m}$. These ash and dust particles can be retained on the microfiltration membrane. The microfiltration membrane has a pore size between 0.05 and $10 \mu \mathrm{m}$ [27]. As for the colors derived from the natural pigment of sugarcane such as chlorophyll is suspected can not be retained by the pore membrane microfiltration. The average particle size of the chlorophyll pigment is $27.26 \pm 3.62 \mathrm{~nm}$. The size of the carotenoid particles varies between $24.2 \mathrm{~nm}-136.1 \mathrm{~nm}$. With these particle sizes, the chlorophyll and carotenoid pigments can be separated, at least with the ultrafiltration membrane. The ultrafiltration membrane has a pore size ranging from 1 - $100 \mathrm{~nm}$ [27].

\section{E. The Coefficient of Membrane Rejection on the Clear Sugarcane Juice Turbidity}

Figure 8 presents the increasing concentration of chitosan and acetic acid, causing an increase in the membrane 
rejection coefficient. In the test results, it is obvious that the smallest turbidity rejection coefficient is the chitosan membrane with a concentration of $2.67 \%$ and $1 \%$ acetic acid with a rejection coefficient value of $22.09 \%$. Membrane with the highest turbidity rejection coefficient value is the chitosan membrane with a concentration of $5.33 \%$ and $2 \%$ acetic acid with a rejection coefficient value of $88.37 \%$.

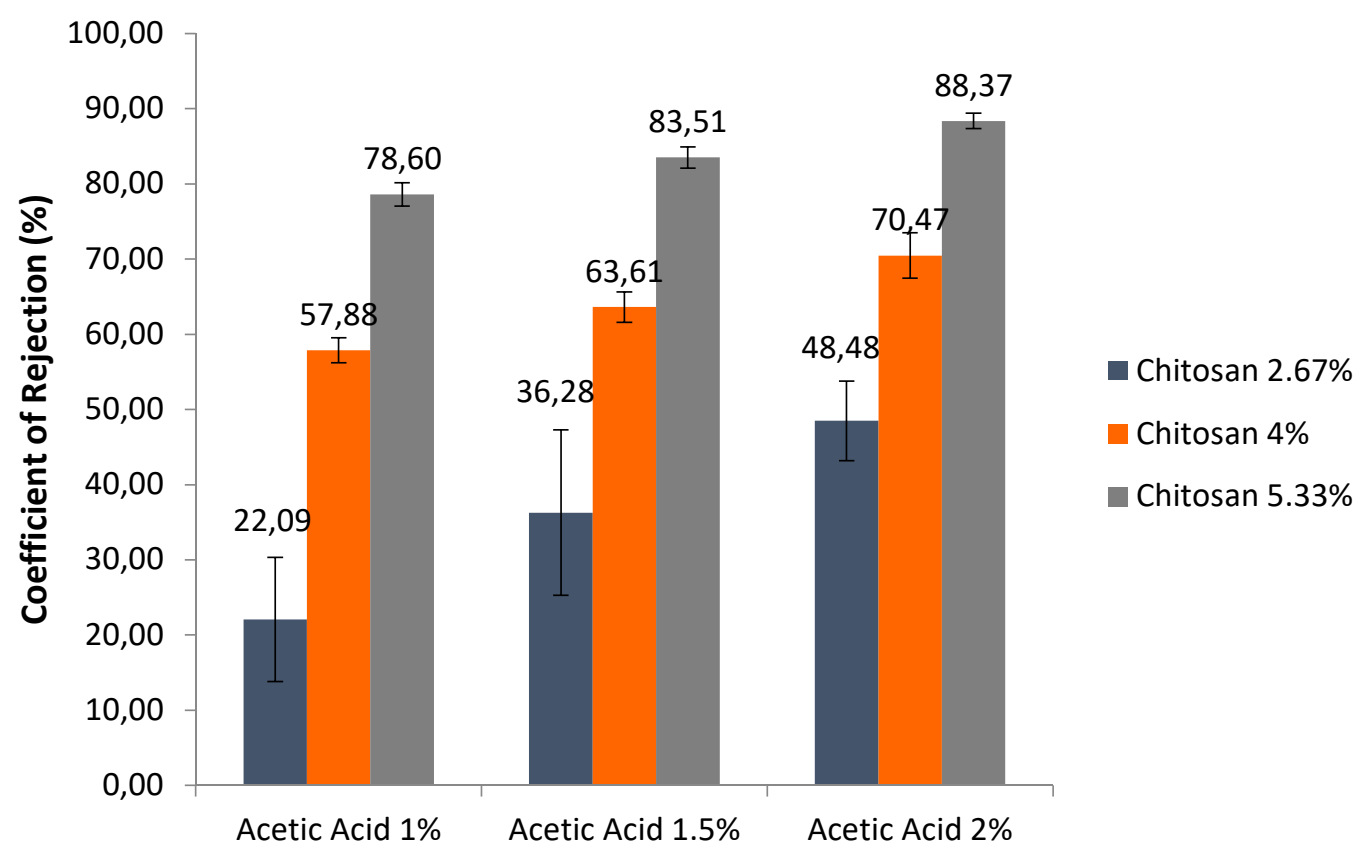

Fig. 8 Effect of chitosan and acetic acid concentration on the rejection of clear sugarcane juice turbidity

This is allegedly due to the higher concentration of chitosan with denser particles, causing the small pore size of the membrane. In addition to higher solvent (acetic acid) concentrations, the solvents will be replaced faster by nonsolvent, which forms small and tight pores. More pores on the membrane will create more surface area, which effectively absorbs the turbidity. Particles that cause turbidity retained by the chitosan membrane through the micro purification process are suspected to be coagulated particles such as juice, wax, pulp, dust, and fiber (cellulose). This statement is in line with research conducted by Agbovi [44] and Zhang [45], which states that the value of water turbidity decreases along with the increasing amount of chitosan used as a filter. Chitosan used as a filter can bind impurities contained in the water. The mechanism of binding the impurities by chitosan is by absorbing and bridging the particles. Once the polymer molecules are in contact with the colloidal particles, some of the groups were absorbed on the surface of the particles.

Particles that cause turbidity retained by the chitosan microfiltration membrane are thought to be ash, starch, lime $(\mathrm{CaO})$, dust, and fiber (cellulose). According to Ghosal [43] the ash has a particle diameter size $>10 \mu \mathrm{m}$. In comparison, Jane [36] reported that the amylum has a particle diameter size ranging from $5-15 \mu \mathrm{m}$. According to Gullett [46], lime $(\mathrm{CaO})$ has a particle diameter size of $\pm 12.10 \mu \mathrm{m}$. Dust particles are subtly divided into sizes ranging from 0.1 to $100 \mu \mathrm{m}$. In comparison, the fiber (cellulose) has a particle diameter size $\pm 25.52 \mu \mathrm{m}$. When compared to the pore size of the microfiltration membrane between 0.05 and $10 \mu \mathrm{m}$ [27], the particles that cause turbidity (ash, starch, lime $(\mathrm{CaO})$, dust, fiber) are much larger than the pore size of the membrane, so it is suspected to be retained on the membrane surface.

Based on the ANOVA calculation, the interaction factor of $\mathrm{K} * \mathrm{~A}$ (Chitosan and Acetic Acid) produced a significant effect (Ftabel $0.05<$ Fcount < Ftabel 0.01). Meanwhile, factor group (repeat), treatment, factor $\mathrm{K}$ (chitosan), and factor A (acetic acid) have a genuine effect (Fcount $>$ Ftabel 0.01 ). Furthermore, LSD was tested with $5 \%$ and $1 \%$ to identify the difference between each treatment interaction. The coefficient of diversity obtained is $6.67 \%$ which is in the category of diversity. Based on the LSD statistical test, it is evident that the wide variation of chitosan and acetic acid has a real difference against the clear sugarcane juice. Nonetheless, some treatments have the same notation. This similarity means that the membranes with such treatments have no significant difference in their effect on measuring the value of clear sugarcane juice clarity.

\section{F. Determination of Best Treatment}

Determination of best treatment is conducted by using multiple attribute method of Zeleny. The parameters used are the permeability coefficient of sugarcane juice, rejection of ICUMSA color, turbidity, and TSS rejection. Based on the calculation, the best treatment is chosen from the treatment having $\mathrm{L} 1, \mathrm{~L} 2$, and $\mathrm{L} \infty$ minimum. The best treatment was obtained at $4 \%$ chitosan membrane treatment and from $1.5 \%$ acetic acid concentration. Chitosan membrane with a chitosan concentration of $4 \%$ and from $1.5 \%$ acetic acid concentration was chosen as the best treatment because it meets the criteria of having a large permeability and rejection. Permeability of sugarcane juice of chitosan membrane with a concentration of $4 \%$ and $1.5 \%$ acetic acid 
concentration reached $116.44 \mathrm{~L} / \mathrm{m}^{2}$.hour.bar, ICUMSA color rejection reached $9.89 \%$, turbidity rejection reached $63.61 \%$, and TSS rejection reached $12.64 \%$.

\section{G. Electron Microscopy Scanning Test Results (SEM)}

The result of SEM analysis on the membrane surface structure shows that there are white particles scattered on the surface of the chitosan membrane, as presented in Fig. 9 and Fig. 10. According to some researchers [47]-[49], the solubility of the polymer in a solvent is limited, resulting in a certain insoluble or saturated concentration. Based on the result of SEM test analysis, it is evident that the chitosan membrane has a pore size, which equals $1.05 \mu \mathrm{m}$.

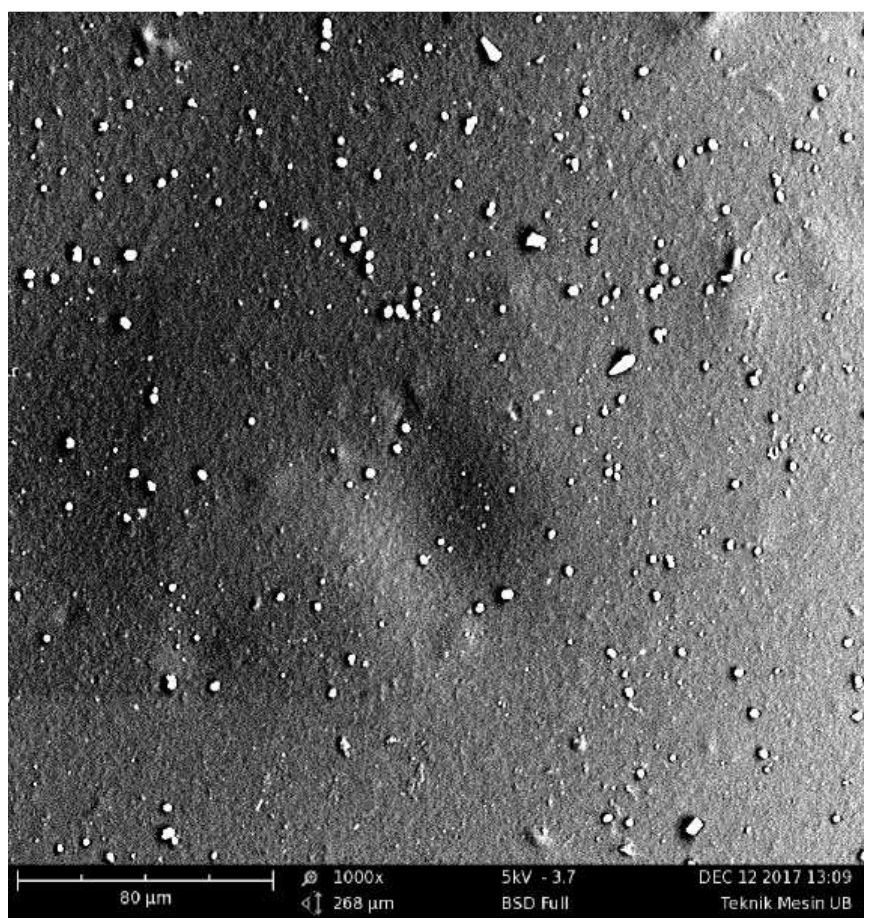

(a)

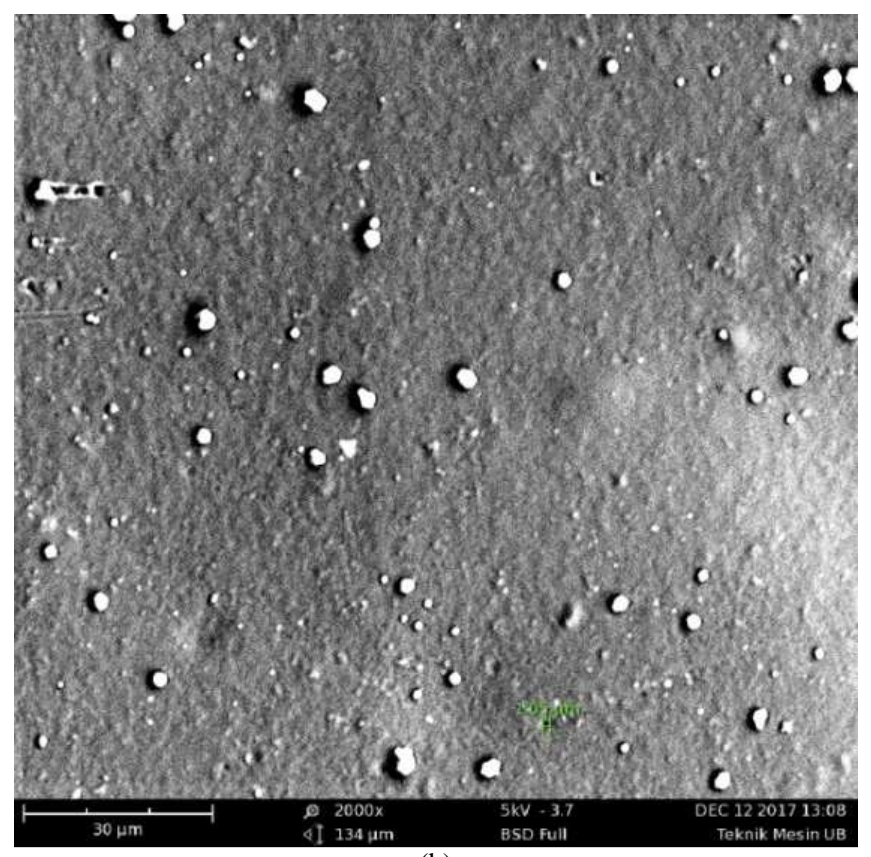

(b)

Fig. 9 SEM analysis on the upper surface of the membrane (a) 1000x magnification, (b) 2000x magnification

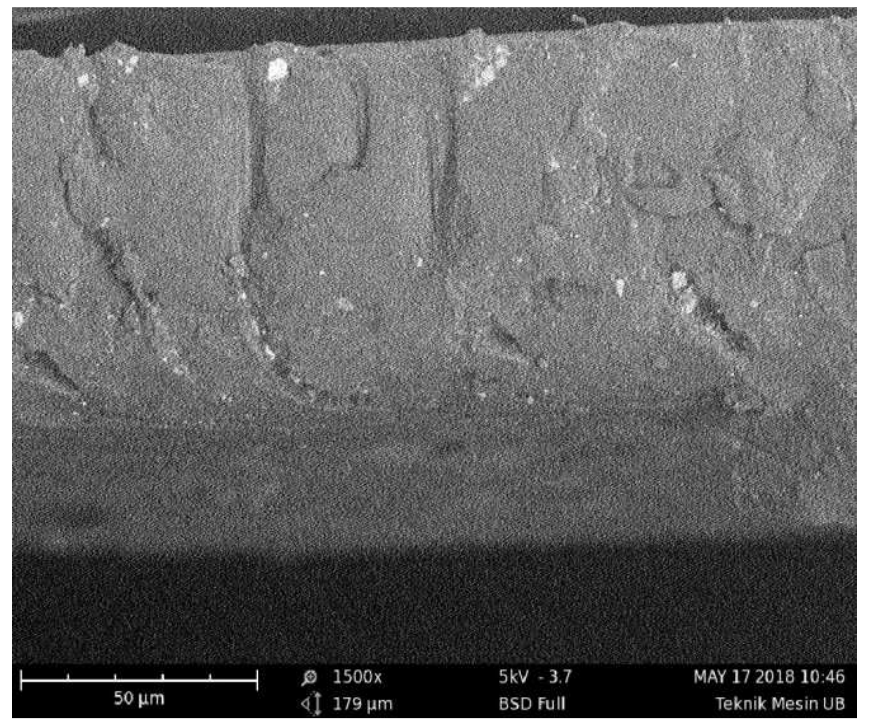

Fig. 10 SEM analysis on the cross-section of the $1500 \mathrm{x}$ magnification membrane

The pore size indicates that the chitosan membrane of the research results includes the micro purification membrane. According to Mulder [27] and Bouchard [50], the micro purification membranes operate at a pressure ranging from 0.1 to 2.0 bar and the permeability limit is greater than 50 $\mathrm{L} / \mathrm{m}^{2}$.hour.bar with a pore size between 0.1 and $10 \mu \mathrm{m}$.

\section{CONCLUSIONS}

In this research, it was found that the treatment of chitosan and acetic acid concentration had a very real effect on the clearance of sugarcane juice. This can be seen from the increasing level of chitosan and acetic acid concentration, causing membrane rejection to Total Soluble Solids (TSS), International Commission for Uniform Methods of Sugar Analysis (ICUMSA) color, and higher sugarcane juice. Greater concentration of polymer (chitosan) will lead to the smaller pore size of the membrane because higher chitosan concentration and denser particles may cause small pore size of the membrane. The higher concentration of acetic acid creates soluble chitosan, which has smoother pores. On the other hand, more insoluble chitosan will cause a hole in the membrane. The best-recommended treatment is a membrane with a chitosan concentration of $2.67 \%$ and from $1.5 \%$ acetic acid concentration with a permeability value of sugarcane juice reaching $116.44 \mathrm{~L} / \mathrm{m}^{2}$.hour.bar; TSS rejection reaching $12.64 \%$, turbidity rejection reaching $63.61 \%$ and rejection on ICUMSA colour reaching $9.89 \%$.

\section{REFERENCES}

[1] Fang, Y., Ellis, A., Uchimiya, M., and Strathmann, T.J. "Selective oxidation of colour-inducing constituents in raw sugar cane juice with potassium permanganate", Food Chemistry, 298, 125036, 2019.

[2] Lemos, S.V., Salgado Jr, A.P., Duerte, A., de Souza Jr, M.A., and Antunes, F.A. "Agroindustrial best practices that contribute to technical efficiency in Brazilian sugar and ethanol production mills", Energy, 177, pp397-411, 2019.

[3] Bano, I., Arshad, M., Yasin, T., Ghauri, M.A., Younus, M. "Chitosan: A potential biopolymer for wound management", International Journal of Biological Macromolecules, 102, pp380-383, 2017.

[4] Adam, M.R., Othman, M.H.D., Samah, R.A., Puteh, M.H., Ismail, A.F., Mustafa, A., Rahman, M.A., and Jaafar, J. "Current trends and future prospects of ammonia removal in wastewater: A 
comprehensive review on adsorptive membrane development", Separation and Purification Technology, 213, pp114-132, 2019.

[5] Ghaemi, N., Daraei, P., Akhlaghi, F.S. "Polyethersulfone nanopurification membrane embedded by chitosan nanoparticles: Fabrication, characterization and performance in nitrate removal from water", Carbohydrate Polymers, 191, pp142-151, 2018

[6] Taghizadeh, M.T., Siyahi, V., Sorkhabi, H.A., and Zarrini, G. "ZnO, $\mathrm{AgCl}$ and $\mathrm{AgCl} / \mathrm{ZnO}$ nanocomposites incorporated chitosan in the form of hydrogel beads for photocatalytic degradation of $\mathrm{MB}, \mathrm{E}$. coli and S. aureus", International Journal of Biological Macromolecules, https://doi.org/10.1016/j.ijbiomac.2019.10.070, 2019.

[7] Malinkina, O.N., Gegel, N.O., and Shipovskaya, A.B. "Hydrodynamic behavior of chitosan hydrochloride macromolecules in aqueous solutions of D- and 1-ascorbic acid", Journal of Molecular Liquids, 284, pp75-81, 2019.

[8] Cheah, W.Y., Show, P.L., Ng, I.S., Lin, G.Y., and Chang, Y.K. "Antibacterial activity of quaternized chitosan modified nanofiber membrane", International Journal of Biological Macromolecules, 126, pp569-577, 2019

[9] Abdolrahimi, M., Seifi, M., and Ramezanzadeh, M.H. "Study the effect of acetic acid on structural, optical and mechanical properties of PVA/chitosan/MWCNT films", Chinese Journal of Physics, 56, pp221-230, 2018.

[10] Cahyaningrum, S.E., Widyastuti, N., and Qomariah, N. "Purification of uric acid using ultra purification membrane chitosanglutaraldehyde-alginate", Research Journal of Pharmaceutical, Biological, and Chemical Sciences, 5(3), pp999-1005, 2014.

[11] Ghani, M., Gharehaghaji, A.A., Arami, M., Takhtkuse, N., and Rezaei, B. "Fabrication of electrospun polyamide-6/chitosan nanofibrous membrane toward anionic dyes removal", Journal of Nanotechnology, 2014, [278418]. DOI: 10.1155/2014/278418, 2014.

[12] Rahimi, Z., Zinatizadeh, A.A., and Zinadini, S. "Preparation and characterization of a high antibiofouling ultrapurification PES membrane using OCMCS-Fe3O4 for application in MBR treating wastewater", Journal of Applied Research in Water and Wastewater 1, pp13-17, 2014

[13] Rupiasih, N.N., Purnomo, R.R., and Sumadiyasa, M. "Preparation and application of chitosan membranes to filter silver from X-ray film processing wastes", Journal of Physics: Conference Series, 710 012009, 2016

[14] Prabhu, K.B., Saidutta, M.B., Isloor, A.M., and Hebbar, R. "Improvement in performance of polysulfone membranes through the incorporation of chitosan - $(3$ - phenyl - 1h - pyrazole - 4 carbaldehyde)", Chemical Engineering, 4, pp1-14, 2017

[15] Li, L., Zhang, J., Li, Y., and Yang, C. "Removal of Cr (VI) with a spiral wound chitosan nanofiber membrane module via dead-end filtration”, Journal of Membrane Science, 544, pp333-341, 2017.

[16] Khoerunnisa, F., Rahmah, W., Ooi, B.S., Dwihermiati, E., Nashrah, N., Fatimah, S., Ko, Y.G., and Ng, E.P. "Chitosan/PEG/MWCNT/Iodine composite membrane with enhanced antibacterial properties for dye wastewater treatment", Journal of Environmental Chemical Engineering, 8(2), 103686, 2020.

[17] Kolenyk, I., Konovalova, V., Kharchenko, K., Burban, A., Kujawa, J., and Kujawski, W. "Enhanced transport and antifouling properties of polyethersulfone membranes modified with $\alpha$-amylase incorporated in chitosan-based polymeric micelles", Journal of Membrane Science, $595,117605,2020$.

[18] Luo, J., Hang, X., Zhai, W., Qi, B., Song, W., Chen, X., and Wan, Y. "Refining sugarcane juice by an integrated membrane process: Purification behavior of polymeric membrane at high temperature", Journal of Membrane Science, 509, pp105-115, 2016.

[19] Bhattacharjee, C., Saxena, V.K., and Dutta, S. "Fruit juice processing using membrane technology: A review", Innovative Food Science \& Technologies, 43, pp136-153, 2017.

[20] Conidi, C., Drioli, E., and Cassano, A. "Membrane-based agro-food production processes for polyphenol separation, purification and concentration", Current Opinion in Food Science, 23, pp149-164, 2018.

[21] Pal, P., Pandey, J.P., and Sen, G. "Grafted sesbania gum: A novel derivative for sugarcane juice clarification", International Journal of Biological Macromolecules, 114, pp349-356, 2018.

[22] Urosevic, T., Povrenovic, D., Vulkasavljevic, P., Urosevic, I., and Stevanovic, S. "Recent developments in microfiltration and ultrafiltration of fruit juices", Food and Bioproducts processing, 106, pp147-161, 2017.

[23] Servi, A.T., Burrieza, E.G., Warsinger, D.M., Livernois, W. Notarangelo, K., Kharaz, J., Lienhard, J.H.V., Arafat, H.A., and
Gleason, K.K. "The effects of iCVD film thickness and conformality on the permeability and wetting of MD membranes", Journal of Membrane Science, 523, pp470-479, 2017.

[24] He, M., Zhang, S., Su, Y., Zhang, R., Liu, Y., and Jiang, Z. "Manipulating membrane surface porosity and pore size by in-situ assembly of Pluronic F127 and tannin", Journal of Membrane Science, 556, pp285-292, 2018.

[25] Swaminathan, J., Chung, H.W., Warsinger, D.M., and Lienhard, J.H. "Energy efficiency of membrane distillation up to high salinity: Evaluating critical system size and optimal membrane thickness", Applied Energy, 211, pp715-734, 2018.

[26] Madsen, H.T., Nissen, S.S., Muff, J., and Sogard, E.G. "Pressure retarded osmosis from hyperjuice solutions: Investigating commercial FO membranes at high pressures", Desalination, 420, pp183-190, 2017.

[27] Huang, T., Chen, J.L., Zhing, T., and Liu, P. "Improving permeability and antifouling performance of poly (ether ether ketone) membranes by photo-induced graft polymerization", Materials Today Communications, 23, 100945, 2020.

[28] Wang, L., Liu, H., Zhang, W., Yu, T, Jin, Q, Fu, B, and Liu, H. "Recovery of organic matters in wastewater by self-forming dynamic membrane bioreactor: Performance and membrane fouling", Chemosphere, 203, pp123-131, 2018.

[29] Liu, Y., Su, Y., Cao, J., Guan, J., Zhang, R., He, M., Fan, L., Zhang, Q., and Jiang, Z. "Antifouling, high-flux oil/water separation carbon nanotube membranes by polymer-mediated surface charging and hydrophilization", Journal of Membrane Science, 542, pp254-263, 2017.

[30] Qian, X., Li, N., Wang, Q., and Ji, S. "Chitosan/graphene oxide mixed matrix membrane with enhanced water permeability for highsalinity water desalination by pervaporation", Desalination, 438, pp83-96, 2018.

[31] Elizalde, C.N., Al-Gharabli, S., Kujawa, J., Mavukkandy, M., Hasan, S.W., and Arafat, H.A. "Fabrication of blend polyvinylidene fluoride/chitosan membranes for enhanced flux and fouling resistance", Separation and Purification Technology, 190, pp68-76, 2018 .

[32] Bakhshayesh, B.E., Imhoff, P.T., and Dentel, S.K. "Assessing clogging of laminated hydrophobic membrane during fecal sludge drying", Science of The Total Environment, 627, pp713-722, 2018.

[33] Melo, N.F.C.B., Soares, B.L.M., Diniz, K.M., Leal, C.F., Canto, D., Flores, M.A.P., Filho, J.H.C.T., Galembeck, A., Stamford, T.L.M., Arnaud, T.M.S., and Stamford, T.C.M. "Effects of fungal chitosan nanoparticles as eco-friendly edible coatings on the quality of postharvest table grapes", Postharvest Biology and Technology, 139 pp56-66, 2018.

[34] Dudek, G., Turczyn, R., and Konieczny, K. "Robust poly(vinyl alcohol) membranes containing chitosan/chitosan derivatives microparticles for pervaporative dehydration of ethanol", Separation and Purification Technology, 234, 116094, 2020.

[35] Shen, Y. and Yang, H. "Effect of preharvest chitosan-g-salicylic acid treatment on postharvest table grape quality, shelf life, and resistance to Botrytis cinerea-induced spoilage", Scientia Horticulturae, 224, pp367-373, 2017

[36] Jane, J., Shen, L., Wang, L., and Maningat, C. "Preparation and Properties of Small - Particle Corn Starch", Journal of Cereal Chemical, 69(3), pp280-283, 1992

[37] Kaszuba, M., McKnight, D., Connah, M., and Watson, F. "Measuring Sub Nanometre Sizes Using Dynamic Light Scattering", Journal of Nanoparticle, 10, pp823-829, 2007.

[38] Erickson, H. "Size and Shape of Protein Molecules at The Nanometer Level Determined by Sedimentation, Gel Filtration, and Electron Microscopy", Journal of Biological Procedures, 11(1), pp32-52, 2009.

[39] Soumya, R., Ghosh, S., and Abraham, E. "Preparation and Characterization of Guar Gum Nanoparticles", International Journal of Biological Macromolecules, 46(2), pp267-269, 2010.

[40] Vainio, U., Maximova, N., Hortling, B., Laine, J., Stenius, P., Simola, L., Gravitis, J., and Serimaa, R. "Morphology of Dry Lignins and Size and Shape of Dissolved Kraft Lignin Particles by X-Ray Scattering", Journal of Langmuir, 20(22), pp9736-9744, 2004.

[41] Nystorm, M., Kaipia, L., and Luque, S. "Fouling and retention of nanopurification membranes", Journal of Membrane Science, 98(3), pp249-262, 1995

[42] Nataraj, S.K., Hosamani, K.M., and Aminabhavi, T.M. "Nanopurification and reverse osmosis thin film composite 
membrane module for the removal of dye and salts from the simulated mixtures", Desalination, 249(1), pp12-17, 2009.

[43] Ghosal, S., Ebert, J., and Self, S. Chemical Composition and Size Distributions for Fly Ashes, Department of Mechanical Engineering, Stanford University, California, 2018.

[44] Agbovi, H.K. and Wilson, L.D. "Design of amphoteric chitosan flocculants for phosphate and turbidity removal in wastewater", Carbohydrate Polymers, 189, pp360-370, 2018.

[45] Zhang, Z., Jing, R., Qian, J., Zhang, K., Ma, G., Chang, X., Zhang, M., and Li, Y. "Coagulation of low temperature and low turbidity water: Adjusting basicity of polyaluminum chloride (PAC) and using chitosan as coagulant aid", Separation and Purification Technology, 206, pp131-139, 2018.

[46] Gullett, B., Blom, J., and Cunningham, R. "Porosity, Surface Area, and Particle Size Effects of $\mathrm{CaO}$ Reacting With $\mathrm{SO}_{2}$ at $1100^{\circ} \mathrm{C}$ ", Journal Reactivity of Solids, 6(2-3), pp263-275, 2001.
[47] Li, X., Zhou, M., Jia, J., and Jia, Q. "A water-insoluble viologenbased $\beta$-cyclodextrin polymer for selective adsorption toward anionic dyes", Reactive and Functional Polymers, 126, pp20-26, 2018.

[48] Thakkar, R., Thakkar, R., Pillai, A., Ashour, E.A., and Repka, M.A "Systematic screening of pharmaceutical polymers for hot melt extrusion processing: a comprehensive review", International Journal of Pharmaceutics, 576, 118989, 2020.

[49] Wu, D., and Ji, Y. "Influence of polymeric excipients on the solubility of aspirin: Experimental measurement and model prediction", Fluid Phase Equilibria, 508, 112450, 2020.

[50] Bouchard, D.M., Benoit, S., Doyen, A., Britten, M., and Pouliot, Y. "Process efficiency of casein separation from milk using polymeric spiral-wound micropurification membranes", Journal of Dairy Science, 100(11), pp8838-8848, 2017. 